University of Nebraska - Lincoln

DigitalCommons@University of Nebraska - Lincoln

2012

\title{
Covariation between understorey light environments and soil resources in Bornean mixed dipterocarp rain forest
}

\author{
Sabrina E. Russo \\ University of Nebraska - Lincoln, srusso2@unl.edu \\ Lin Zhang \\ University of Nebraska-Lincoln \\ Sylvester Tan \\ Harvard University, sylt@pd.jaring.my
}

Follow this and additional works at: https://digitalcommons.unl.edu/bioscifacpub

Russo, Sabrina E.; Zhang, Lin; and Tan, Sylvester, "Covariation between understorey light environments and soil resources in Bornean mixed dipterocarp rain forest" (2012). Faculty Publications in the Biological Sciences. 258.

https://digitalcommons.unl.edu/bioscifacpub/258

This Article is brought to you for free and open access by the Papers in the Biological Sciences at DigitalCommons@University of Nebraska - Lincoln. It has been accepted for inclusion in Faculty Publications in the Biological Sciences by an authorized administrator of DigitalCommons@University of Nebraska - Lincoln. 


\title{
Covariation between understorey light environments and soil resources in Bornean mixed dipterocarp rain forest
}

\author{
Sabrina E. Russo*, 1, Lin Zhang† and Sylvester Tan $\ddagger$ \\ * School of Biological Sciences, University of Nebraska, Lincoln, Nebraska, 68588 USA \\ $\dagger$ Department of Statistics, University of Nebraska, Lincoln, Nebraska, 68588 USA \\ $\ddagger$ Center for Tropical Forest Science - Arnold Arboretum Asia Program, Harvard University, Cambridge, MA USA 02138 \\ (Accepted 22 September 2011)
}

\begin{abstract}
Variation in understorey irradiance is both a cause and consequence of the structure and dynamics of closed-canopy forests, which are also influenced by soil nutrients and water availability. We tested the hypothesis that understorey light regimes differ among four mixed dipterocarp forest types that share the same rainfall, but grow on different soils along an edaphic gradient at one site in Borneo. Based on data from photosynthetically active radiation sensors deployed at 1-m height at 36 locations for 351 sensor-days, we found significant soil-related variation in irradiance. The more productive forest types on clay and fine loam had lower daily photosynthetic photon flux density (PPFD) than those on the more nutrient-depleted and better-drained sandy loam and loam. They also had fewer moderate to high-intensity sunflecks, and a greater proportion of their daily PPFD came from low-intensity light. Understorey irradiance did not, however, monotonically decline with increasing soil resources. Forests on intermediate soils had greater irradiance than those with more and less soil resources, due to steeper slopes. Plant communities arrayed on resource gradients are commonly used to test hypotheses of environmental factors driving their assembly. Our results indicate that consideration of multiple resource dimensions in such tests is critical.
\end{abstract}

Key Words: environmental gradients, forest understorey, Malaysia, soil texture, sunflecks, tree regeneration, tropical forest

\section{INTRODUCTION}

Community-level patterns in plant species diversity, composition and functional-trait variation are often linked to differences in resource availability along environmental gradients (McGill et al. 2006), which are often defined with respect to the resources required for plant growth and survival (soil mineral nutrients, water and light). Gradients defined with respect to one resource may nonetheless also vary with respect to other resources. For example, forests growing on soils of different texture or along elevation gradients often have different disturbance regimes, creating covariation between these environmental factors and light (Matson \& Boone 1984, Myster \& Fernandez 1995, Ohkubo 2007a, 2007b; Richards 1996, Wells et al. 1998).

\footnotetext{
${ }^{1}$ Corresponding author. Email: srusso2@unl.edu
}

Feedbacks involving differential plant growth provide a mechanism by which resources can vary in disparate ways along gradients (Chapin et al. 1987, Pearson et al. 2003). Denser forest canopies have been observed to grow on more fertile, moister soils, casting greater shade in the understorey (Ashton 1964, Ashton \& Hall 1992, Coomes \& Grubb 1996). The degree of shading results from several interacting characteristics of the overstorey, including the biomass of leaves and their sizes, inclinations and longevities and the branching structure of tree crowns (Coomes \& Grubb 2000). Variation in light environments between canopy gaps of different sizes and the forest understorey is well-documented (Chazdon \& Fetcher 1984, Dalling et al. 1998, Denslow et al. 1998, Hartshorn 1980, Whitmore 1978), and there is also widespread evidence of finer-scale spatial variation in understorey light among microhabitats within closedcanopy forest (Canham et al. 1994, Coomes et al. 2005, Montgomery \& Chazdon 2001, Poorter \& Arets 2003, Whitmore \& Wong 1959, Yoda 1974). What remains poorly understood is how understorey light regimes vary 
between neighbouring closed-canopy forest types that experience the same rainfall, but grow on different soil types.

Quantifying soil-related differences in understorey irradiance is important for understanding the growth and competitive interactions of juvenile trees because even small differences in photosynthetic photon flux density (PPFD) and the frequency and intensity of sunflecks, short bursts of direct photosynthetically active radiation (PAR), affect carbon gain (Chazdon 1986, Koizumi \& Oshima 1993, Leakey et al. 2003, 2005; Zipperlen \& Press 1997). Furthermore, light-defined niches of tree species can be finely partitioned (Barker et al. 1997), even among shadetolerant tree species (Kobe 1999, Montgomery \& Chazdon 2002, Poorter \& Arets 2003). Recent studies have found a greater diversity of light-defined niches in forests on morefertile, moist soil, compared with adjacent soil types that were more nutrient-limited and well-drained (Coomes et al. 2009).

We used an edaphic gradient underlying mixed dipterocarp forest in Malaysian Borneo to investigate covariation between the availabilities of understorey light and soil resources. This region is well-known for having a high turnover of tree species between soil-defined forest types (Ashton 1964, Baillie et al. 1987, Brunig 1974) due to specialization of species on different soils (Davies et al. 2005, Paoli et al. 2006, Potts et al. 2002). We tested the hypothesis that regimes of PAR differ significantly in the understorey of rain forest growing on four soil types along an edaphic gradient in Borneo. Soils along this gradient range from coarse loams that are sandstonederived, nutrient-depleted and well-drained, to clays that are shale-derived, less nutrient-depleted and less welldrained (Baillie et al. 2006, Russo et al. 2010, Tan et al. 2009), but the forests share the same rainfall regime, as they are located at one site. Variation in light regimes between and within forest types was characterized in terms of total daily PPFD and the frequency, duration and intensity of sunflecks and in terms of their seasonal variation between the non-monsoon season and the generally cloudier, early monsoon season.

\section{METHODS}

\section{Study site}

This research was conducted in Lambir Hills National Park, Sarawak, Malaysia $\left(4^{\circ} 11^{\prime} \mathrm{N}, 114^{\circ} 01^{\prime} \mathrm{E}\right)$. The Park encompasses 6800 ha of lowland mixed dipterocarp forest with the highest tree species richness recorded in the Palaeotropics (Ashton \& Hall 1992, Lee et al. 2002). Rainfall is c. $3000 \mathrm{~mm} \mathrm{y}^{-1}$, with all months averaging $>100 \mathrm{~mm}$ (Watson 1985). Despite the lack of a well-defined dry season, there is seasonal variation in rainfall (Palmiotto 1998): the monsoon season, which brings greater monthly average rainfall, occurs approximately from November to February, with other times of year receiving less rainfall. In 1991, a 52-ha plot (hereafter, Lambir) was established in the Park following standardized methods (Condit 1998) and pegged with permanent markers at every 20-m grid corner (Figure 1). Floristic composition, stand structure, soils, soil nutrient and water contents, and geomorphology of Lambir are described elsewhere (Baillie et al. 2006, Lee et al. 2002, Russo et al. 2010, Tan et al. 2009).

The high species richness of this region is at least partly attributable to high beta-diversity, arising from substantial turnover of tree species composition between soil-defined habitats (Ashton 1964, Baillie et al. 1987, Potts et al. 2002). Soils range from coarse loams that are sandstone-derived, leached, nutrient-depleted and well-drained, with substantial raw humus, to clays that are shale-derived, less nutrient-depleted and less welldrained, with little raw humus. The distributions of most tree species in Lambir are strongly biased with respect to four soil habitats defined based on variation in nutrients (total $\mathrm{C}, \mathrm{N}$ and $\mathrm{P}$, and exchangeable $\mathrm{K}, \mathrm{Ca}$ and $\mathrm{Mg}$ ) and elevation at a $20 \times 20-\mathrm{m}$ scale (Davies et al. 2005). Ranked in ascending order of nutrient content and descending order of particle size, they are: sandy loam, loam, fine loam and clay (Table 1). In addition to variation in mineral nutrients, soil volumetric water content at $0-10 \mathrm{~cm}$ depth is significantly higher on the clay, relative to sandy loam, at all times of year (Russo et al. 2010). Furthermore, elevation and slope vary significantly among soil types: the sandy loam and clay soils occur at the highest and lowest elevations, respectively, and the loam and fine loam soils occur at intermediate elevations in Lambir (Baillie et al. 2006). The loam and fine loam soils are located on steep slopes, where there are more frequent landslips (Ohkubo 2007a, 2007b).

\section{Measurement of understorey light and slope}

Photosynthetic photon flux density (PPFD) was measured in the understorey of forest on each of the four soil types using photosynthetically active radiation (PAR) sensors (LI-190SA quantum sensor, LiCor Biosciences, Lincoln, Nebraska, USA) from 8 November-7 December 2007 and 28 May-21 June 2008. The first sampling period represents the early monsoon season, whereas the second sampling period (non-monsoon season) encompasses a period of relatively less rainfall. Sensors were arrayed in groups of three at randomly selected $20 \times 20$-m grid points (locations) on each soil type. Each sensor was placed $5 \mathrm{~m}$ from the grid point, in one of the four directions parallel to the plot axes. Sensors were mounted on tripods 
Table 1. Mean total nitrogen (\%), total phosphorus $\left(\mathrm{mg} \mathrm{kg}^{-1}\right)$, $\mathrm{pH}$, exchangeable magnesium $\left(\mathrm{cmol}_{\mathrm{c}} \mathrm{kg}^{-1}\right)$ and calcium $\left(\mathrm{cmol}_{\mathrm{c}} \mathrm{kg}^{-1}\right)$, and elevation (m) for the four soil types in the Lambir plot (Davies et al. 2005). Significant differences among soil types are indicated by different lowercase letters, with standard errors following the means.

\begin{tabular}{|c|c|c|c|c|c|c|c|}
\hline Soil type & $\mathrm{N}$ & Total N & Total P & $\mathrm{pH}$ & $\mathrm{Mg}$ & $\mathrm{Ca}$ & Elevation \\
\hline Sandy loam & 766 & $0.093 \pm 0.001^{\mathrm{a}}$ & $43.7 \pm 0.7^{\mathrm{d}}$ & $4.64 \pm 0.01^{\mathrm{a}}$ & $0.12 \pm 0.01^{\mathrm{d}}$ & $0.21 \pm 0.01^{\mathrm{c}}$ & $193.8 \pm 0.7^{\mathrm{a}}$ \\
\hline Loam & 184 & $0.099 \pm 0.003^{\mathrm{a}, \mathrm{c}}$ & $66.5 \pm 2.3^{c}$ & $4.41 \pm 0.01^{b}$ & $0.15 \pm 0.01^{\mathrm{c}}$ & $0.22 \pm 0.01^{\mathrm{c}}$ & $183.1 \pm 1.4^{\mathrm{b}}$ \\
\hline Fine loam & 270 & $0.107 \pm 0.002^{\mathrm{b}}$ & $103.3 \pm 2.2^{b}$ & $4.32 \pm 0.01^{\mathrm{c}}$ & $0.19 \pm 0.01^{b}$ & $0.30 \pm 0.00^{b}$ & $152.6 \pm 1.4^{\mathrm{c}}$ \\
\hline Clay & 80 & $0.107 \pm 0.003^{b, c}$ & $133.6 \pm 4.1^{\mathrm{a}}$ & $4.43 \pm 0.04^{b}$ & $0.70 \pm 0.04^{\mathrm{a}}$ & $0.52 \pm 0.01^{\mathrm{a}}$ & $138.8 \pm 1.7^{\mathrm{d}}$ \\
\hline
\end{tabular}

and levelled at a height of $1 \mathrm{~m}$. Sensors were kept at each location for $72 \mathrm{~h}$ then moved to a new location. In 2007 , seven locations each were sampled on the loam and fine loam soils, and 14 locations each were sampled on the sandy loam and clay soils, for a total of 189 sensordays; in 2008, six and 12 locations, respectively, were sampled, for a total of 162 sensor-days. This placement of sensors was designed to sample spatial variation in light within soil types at both coarse scales (variation among locations) and fine scales (variation among sensors within a location).

PPFD from each sensor was recorded using batterypowered data-loggers (CR-800 and CR-1000; Campbell Scientific, Logan, Utah, USA). In 2007, data were scanned every $5 \mathrm{~s}$, with average, maximum and total PPFD recorded every $15 \mathrm{~min}$ and $24 \mathrm{~h}$. In 2008, data were scanned and recorded every second, with average, maximum and total PPFD recorded every $15 \mathrm{~min}$ and $24 \mathrm{~h}$. Two PAR sensors were mounted in a tower $<1$ $\mathrm{km}$ from the plot, over the forest canopy and completely exposed to the sky, measuring the maximum possible PPFD given cloud-cover. Data from the canopy and understorey sensors were recorded at the same frequency.

The slope in degrees was calculated using standard methods (Condit 1998) for each location, based on elevation data from the Lambir plot. Four slopes were calculated from the four corners of each $20 \times 20-\mathrm{m}$ quadrat surrounding each location, and the average was used.

\section{Statistical analysis}

Total daily PPFD was calculated in the understorey and over the canopy for each sensor-day based on the 15-min totalized data from 06h00-18h00 in 2007 and 2008. Relative total daily PPFD (hereafter, relative PPFD) in the understorey was calculated as a percentage of the above-canopy PPFD (the average of data from the two sensors) on that day ((understorey PPFD/over-canopy PPFD) $\times 100)$. Relative PPFD was analysed using a linear, mixed-effects model with normally distributed errors using the Mixed Procedure in SAS software version 9.2 (SAS Institute Inc., Cary, NC, USA). Slope, soil type and their interaction were treated as fixed effects, and location, sampling date (date) and sensor number (sensor) were treated as nested random effects: location (habitat), date (location) and sensor (location), where the parentheses indicate the grouping variable within which effects were nested. For purposes of variance partitioning, all effects were treated as fixed effects in order to calculate coefficients of determination for each. Relative PPFD was logarithmically transformed prior to analysis to improve normality of residuals. Over-canopy PPFD was used to test for seasonal differences in light availability using a general linear model with normally distributed errors and season (early monsoon or non-monsoon) as a fixed effect.

The frequency of sunflecks in 2007 and 2008 was modelled as a binomial process, $m_{j} \sim \operatorname{Binomial}\left(N_{j}, p_{j}\right)$, where $N_{j}$ is the total number of 15 -min sampling intervals in a day from $06 \mathrm{~h} 00-18 \mathrm{~h} 00, m_{j}$ is the number of those 15-min intervals in which the maximum PPFD exceeded 20, 50 or $100 \mu \mathrm{mol} \mathrm{m}{ }^{-2} \mathrm{~s}^{-1}$, and $p_{j}$ is the expected probability of a sunfleck occurring in an interval. Thus, a 15-min interval was categorized as having experienced a sunfleck of low, medium or high intensity based on whether the maximum PPFD exceeded 20, 50 or 100 $\mu \mathrm{mol} \mathrm{m}^{-2} \mathrm{~s}^{-1}$ in that interval. These thresholds of light intensity were selected based on previous definitions of sunflecks (Chazdon \& Fetcher 1984, Koizumi \& Oshima 1993). Variation in the expected probability of a sunfleck occurring was analysed using generalized linear mixedeffect models employing a logit link function (McCullach \& Nelder 1989) using the Glimmix Procedure in SAS software version 9.2 (SAS Institute Inc., Cary, NC, USA). Slope, soil type and their interaction were treated as fixed effects, and location, date and sensor were treated as nested random effects, as in the analyses of relative PPFD. Data from 2007 and 2008 were analysed separately for both relative PPFD and sunfleck probability, because one set of locations that was sampled in 2007 was not sampled in 2008. To identify seasonal differences, statistical tests were also performed for the identical subset of locations that were sampled in both seasons. The probability distribution of the maximum PPFD within a 15-min interval, across all sampling sensors, locations and days within a soil type and season were tested for differences (1) between forests on different soil types in the same season and (2) between seasons in forests on the same soil type. The latter comparisons used the identical set of locations 
for both seasons. These differences were identified using a series of two-sample Komolgorov-Smirnov tests, which test whether two empirical distributions come from the same probability distribution.

To assess patterns in dynamic radiation at finer temporal scales, PPFD was also scanned and recorded at 1 -s intervals in 2008. The number of seconds (duration) during which PPFD fell within eight intensity bins was counted at each sensor location from 06h00-18h00 over $18 \mathrm{~d}$. The independence of sunfleck duration and intensity across soil types was tested using log-linear models on the binned data (Agresti 1990). For each sensor location, the per cent of total PPFD contributed by sunflecks of different intensities was also calculated. Differences due to soil type and slope were tested using multivariate analysis of variance (MANOVA). Data were squareroot transformed to improve normality. Model selection using Akaike's Information Criterion (AIC) (Burnham \& Anderson 2002) was used to select the best-supported model for all analyses.

\section{RESULTS}

\section{Seasonal variation in total daily photosynthetic photon flux density}

Above the forest canopy, total daily PPFD was significantly higher in the non-monsoon than the monsoon season $\left(F_{(1.65)}=5.31, \mathrm{P}=0.024\right)$. Total daily PPFD averaged $( \pm S E) 35.6 \pm 0.16 \mathrm{~mol} \mathrm{~m}^{-2}$ in the nonmonsoon season and $31.2 \pm 0.15 \mathrm{~mol} \mathrm{~m}^{-2}$ in the early monsoon season.

\section{Soil-related variation in total daily photosynthetic photon flux density}

The slope of the locations at which PPFD was sampled differed significantly among soil types $\left(F_{(3,38)}=9.53, \mathrm{P}<\right.$ 0.001). Loam was steeper than all other soil types (all $\mathrm{P}<$ 0.005), but no other comparisons differed significantly. For both seasons, slope correlated strongly with total daily PPFD only in the understorey of forest on loam soil (Table 2). However, the model with only the main effect of forest type had the lowest AIC for all data sets, and so the effect of slope and its interaction with forest type were removed ( $\triangle$ AIC relative to the full model: early monsoon season, all locations, 25.3; early monsoon season, subset of locations sampled in both years, 24.1; non-monsoon season, 17.5). Variation between the forests on the four different soil types in total daily PPFD at 1-m height explained $13 \%$ and $11 \%$ of the total variation in PPFD in the early monsoon and non-monsoon season, respectively. The PPFD varied significantly among these
Table 2. Correlations between slope and total daily photosynthetic photon flux density in the understorey of four forest types in Borneo underlain by sandy loam, loam, fine loam and clay in the early monsoon and non-monsoon seasons.

\begin{tabular}{lcc}
\hline Forest type & $\mathrm{r}$ & $\mathrm{P}$ \\
\hline Early monsoon season - all locations & \\
Sandy loam & -0.06 & 0.539 \\
Loam & 0.31 & 0.016 \\
Fine loam & -0.02 & 0.888 \\
Clay & 0.04 & 0.661 \\
Early monsoon season - locations sampled in both seasons \\
Sandy loam & 0.02 & 0.830 \\
Loam & 0.30 & 0.038 \\
Fine loam & -0.23 & 0.090 \\
Clay & 0.07 & 0.457 \\
Non-monsoon season & & \\
Sandy loam & -0.19 & 0.044 \\
Loam & 0.38 & 0.005 \\
Fine loam & -0.18 & 0.191 \\
Clay & 0.20 & 0.041 \\
\hline
\end{tabular}

forests in both the early monsoon season (Figure 2a; all locations: $F_{(3,38)}=3.63, \mathrm{P}=0.021$; subset of locations sampled in both seasons: $\left.F_{(3,32)}=3.29, \mathrm{P}=0.033\right)$ and non-monsoon seasons (Figure $2 \mathrm{~b} ; F_{(3,32)}=3.10, \mathrm{P}=$ 0.040). Overall, the dominant pattern in both seasons was that forest on the clay soil had the darkest understorey and that forest on loam and fine loam had the brightest understorey, but which comparisons showed statistically significant differences were not always consistent. In the early monsoon season, the forest understorey on clay was significantly darker than on both loam and fine loam (based on all locations sampled) and than on loam only (based on locations sampled in both seasons). In the non-monsoon season, the forest understorey on clay was significantly darker than on both sandy loam and loam. In the early monsoon season, the forest understorey on loam also had significantly greater PPFD than did the sandy loam, based on locations sampled in both seasons. The disparate results between datasets based on all locations sampled were largely due to one location on fine loam near a large gap from a landslip that was sampled in the early monsoon, but not the non-monsoon, season.

Within forest types, course- and fine-scale spatial effects accounted for more of the total variation in PPFD than did temporal effects. Variation between locations within a forest type (coarse scale) and between sensors at a location (fine scale) accounted for $45 \%$ and $37 \%$ in the early monsoon season (all locations) and for $41 \%$ and $41 \%$ in the non-monsoon season, respectively, of the total variation in PPFD. In contrast, variation in PPFD among days at a location accounted for only $3 \%$ and $4 \%$ of the total variation in PPFD in the early monsoon (all locations) and non-monsoon seasons, respectively. 
Table 3. Significant differences within the understorey of Bornean rain forest growing on four soil types in the frequency of sunflecks of low, medium and high intensity ( $>20,>50$ and $>100 \mu \mathrm{mol} \mathrm{m}^{-2} \mathrm{~s}^{-1}$, respectively) in two seasons. Sunflecks were defined based on the maximum photosynthetic photon flux density observed in 15-min intervals. Test statistics are shown for the main effect of forest type, with numerator and denominator degrees of freedom (ndf and ddf, respectively). Statistically significant post hoc comparisons between forest types, tested after finding a statistically significant main effect of forest type, were assessed at $\mathrm{P}<0.05$. Abbreviations for forest types: $\mathrm{SL}=$ forest on sandy loam; $\mathrm{L}=$ forest on loam; $\mathrm{FL}=$ forest on fine loam; $\mathrm{C}=$ forest on clay.

\begin{tabular}{|c|c|c|c|}
\hline Sunfleck intensity & F-value (ndf, ddf) & $\mathrm{P}$ & Significant post hoc comparisons \\
\hline \multicolumn{4}{|c|}{ Early monsoon season - all locations } \\
\hline Low & $3.50(3,37.3)$ & 0.025 & $\mathrm{C}<\mathrm{SL}, \mathrm{C}<\mathrm{L}, \mathrm{C}<\mathrm{FL}$ \\
\hline Medium & $3.22(3,36.6)$ & 0.034 & $\mathrm{C}<\mathrm{SL}, \mathrm{C}<\mathrm{L}, \mathrm{C}<\mathrm{FL}$ \\
\hline High & $2.42(3,35.6)$ & 0.082 & - \\
\hline \multicolumn{4}{|c|}{ Early monsoon season - locations sampled in both seasons } \\
\hline Low & $2.33(3,31.3)$ & 0.093 & - \\
\hline Medium & $2.12(3,31.3)$ & 0.118 & - \\
\hline High & $1.99(3,30.5)$ & 0.136 & - \\
\hline \multicolumn{4}{|c|}{ Non-monsoon season } \\
\hline Low & $3.39(3,29.9)$ & 0.031 & $\mathrm{C}<\mathrm{SL}, \mathrm{C}<\mathrm{L}, \mathrm{FL}<\mathrm{SL}$ \\
\hline Medium & $2.97(3,28.9)$ & 0.049 & $\mathrm{C}<\mathrm{SL}$ \\
\hline High & $2.56(3,28.7)$ & 0.074 & - \\
\hline
\end{tabular}

\section{Soil-related variation in frequency and intensity of sunflecks}

Forests types differed strongly in the frequency of understorey sunflecks of different intensities in the early monsoon (Figure 3a) and non-monsoon (Figure 3b) seasons, based on data recorded every $15 \mathrm{~min}$. In all within-season pairwise comparisons of forests on different soils, the probability distributions of maximum PPFD for each soil type were significantly different from each other (all $\mathrm{P}<0.001$ ). Forests on the same soil type also differed in their probability distributions of maximum PPFD across seasons (all $\mathrm{P}<0$. 001).

The model with only the main effect of forest type had the lowest AIC for all data sets, and so the effect of slope and its interaction with forest type were removed from models. The frequency of sunflecks with low and medium, but not high, intensities varied significantly among forest types in both the early monsoon and non-monsoon seasons, but differences among forest types in sunfleck frequency and intensity shifted between seasons (Table 3). In the early monsoon season, based on all sampled locations, the forest on clay had the lowest frequency of low- and medium-intensity sunflecks, whereas the forest on sandy loam was intermediate in frequency of low- and mediumintensity sunflecks. The forest on loam had the highest frequency of low-intensity sunflecks, and the forest on fine loam had the highest frequency of medium-intensity sunflecks. Based only on locations sampled in both

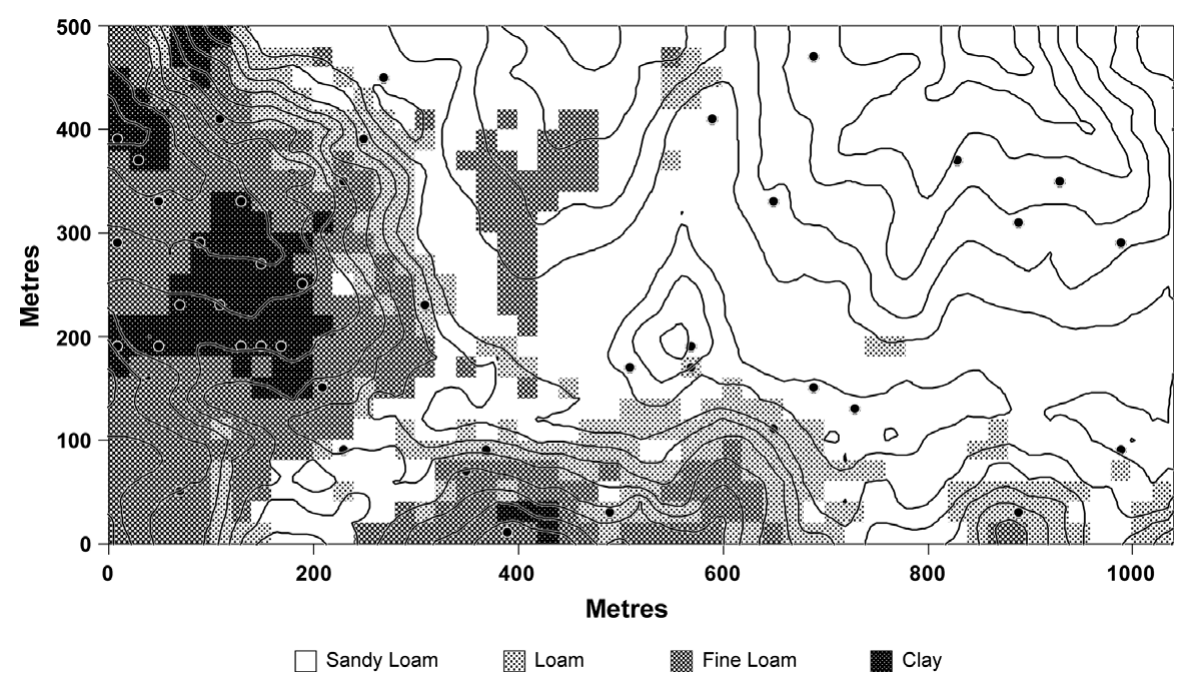

Figure 1. Map of the 52- ha forest dynamics plot at Lambir Hills National Park, Malaysian Borneo, showing soil types, elevation contours (14 m) and sampling locations (filled circles). 
(a) Early monsoon

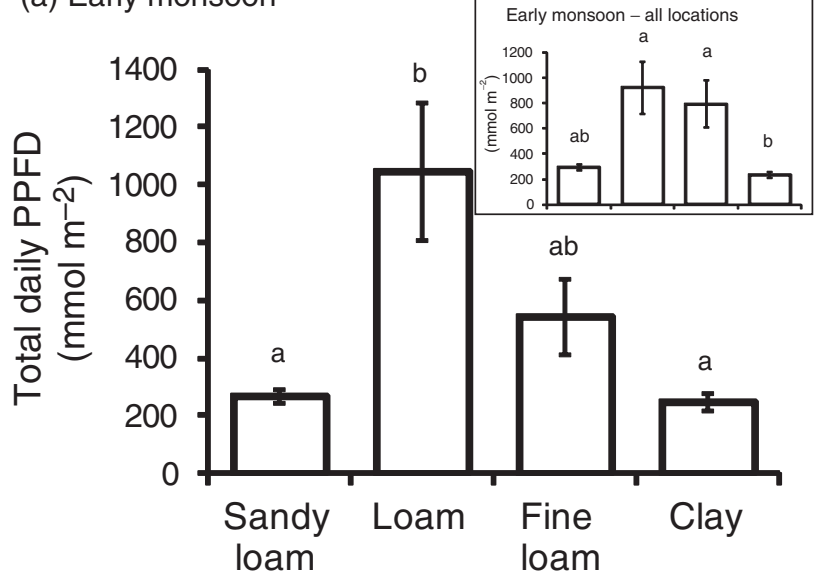

Forest type

(b) Non-monsoon

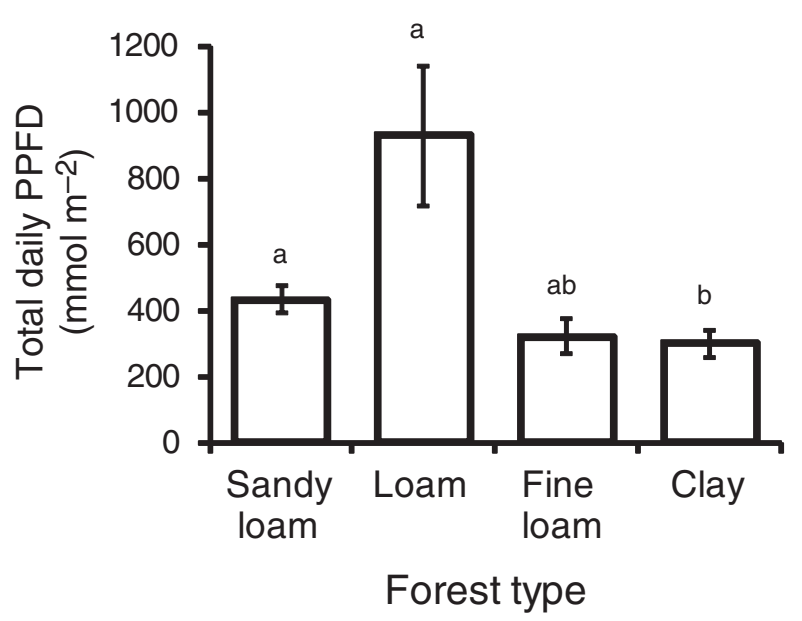

Figure 2. Average total daily photosynthetic photon flux density (PPFD) in the understorey of Bornean rain forest underlain by four soil types. The inset shows comparisons between forest types in the early monsoon season (November 2007) based on all sampled locations (189 sensordays at 7 (loam and fine loam) and 14 (sandy loam and clay) locations per forest type), and the main chart shows comparisons based on the subset of those locations that were also sampled in the monsoon season (a). The main chart shows comparisons between forest types in the nonmonsoon season (May 2008; 162 sensor-days at 6 (loam and fine loam) and 12 (sandy loam and clay) locations per forest type) (b). Error bars are \pm 1 SE. Different letters over bars indicate significant differences between soil types, based on relative PPFD.

seasons, however, there were no significant differences among the forests in the early monsoon season. In the non-monsoon season, the forest on clay again had the lowest frequency of low- and medium-intensity sunflecks, but, in contrast to the wetter season, the forest on sandy loam had the highest frequency of low- and mediumintensity sunflecks. The forests on loam and fine loam were intermediate in the frequency of low- and mediumintensity sunflecks.
Based on PPFD recorded every second during the monsoon season, the duration and intensity of sunflecks differed significantly across forest types. The log-linear model with all effects and interactions had the lowest AIC (448), and a likelihood ratio test strongly favoured inclusion of the three-way interaction $(\mathrm{P}<0.001)$, indicating that sunfleck intensities and durations were not independent across soil types. Both long-duration and high-intensity sunflecks were rare on all soil types. The understorey of forest on sandy loam and loam had higher frequencies of moderate to high-intensity sunflecks, compared with the fine loam and clay soils, where PPFD was more concentrated into short-duration sunflecks of low-intensity. These patterns in sunfleck intensity were confirmed in analyses of the per cent of total PPFD received in $3 \mathrm{~d}$ at locations on each soil type (Figure 4). The effect of forest type on the multivariate variance in PPFD was significant (Pillai's $P=0.420$, $d f=3, \mathrm{P}=0.006)$. Univariate tests within each sunfleck PPFD category revealed that more of the total PPFD in the understorey of fine loam and clay was contributed by the lowest intensity sunflecks, compared with sandy loam and loam. In contrast, the per cent of the total PPFD contributed by moderate- to high-intensity sunflecks was higher in the sandy loam and loam understorey, compared with fine loam and clay. However, forest types differed in the relationship between slope and the per cent of total PPFD contributed by sunflecks of differing intensities, and this effect was strongest for the forest type on loam, which had the steepest slopes (forest typeslope interaction: Pillai's $P=0.411, d f=3, \mathrm{P}=0.008$; Figure 5). Univariate tests within each sunfleck category demonstrated that for the understorey on sandy loam, clay, and fine loam, slope had no effect on the per cent of total PPFD contributed by sunflecks of any intensity, except that on fine loam, steeper locations had a lower per cent contributed by high intensity sunflecks (100-500 $\mu \mathrm{mol} \mathrm{m}{ }^{-2} \mathrm{~s}^{-1}$; Figure $5 \mathrm{~d}$ ). In contrast, on loam, locations with steeper slopes had a greater per cent of total PPFD contributed by high-intensity sunflecks (25-50 and 50$100 \mu \mathrm{mol} \mathrm{m}^{-2} \mathrm{~s}^{-1}$; Figure $5 \mathrm{~b}$ and $5 \mathrm{c}$ ), but had a lower per cent contributed by the lowest intensity sunflecks $(0-5$ $\mu \mathrm{mol} \mathrm{m}^{-2} \mathrm{~s}^{-1}$; Figure 5a).

\section{DISCUSSION}

The light regimes that juvenile trees experience in the understorey of closed-canopy forest have a profound influence on above-ground competitive interactions, life histories and allometries of trees as they vie for a position in the canopy (Pickett \& White 1987), with consequences for the maintenance of species diversity (Ricklefs 1977). Variation in light regimes is, however, both a cause and consequence of above-ground vegetation, the structure 
(a) Early monsoon

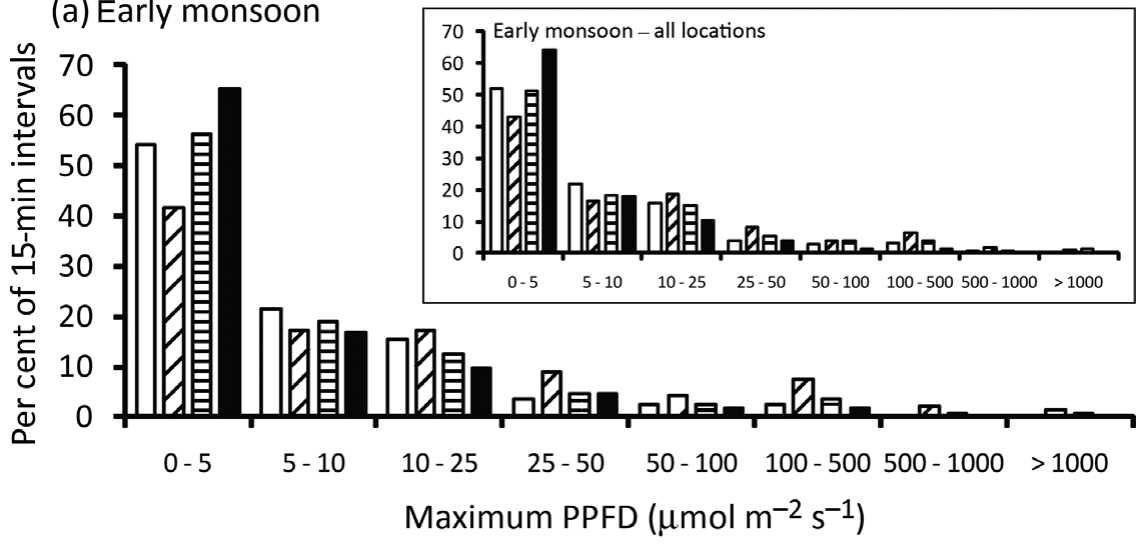

(b) Non-monsoon

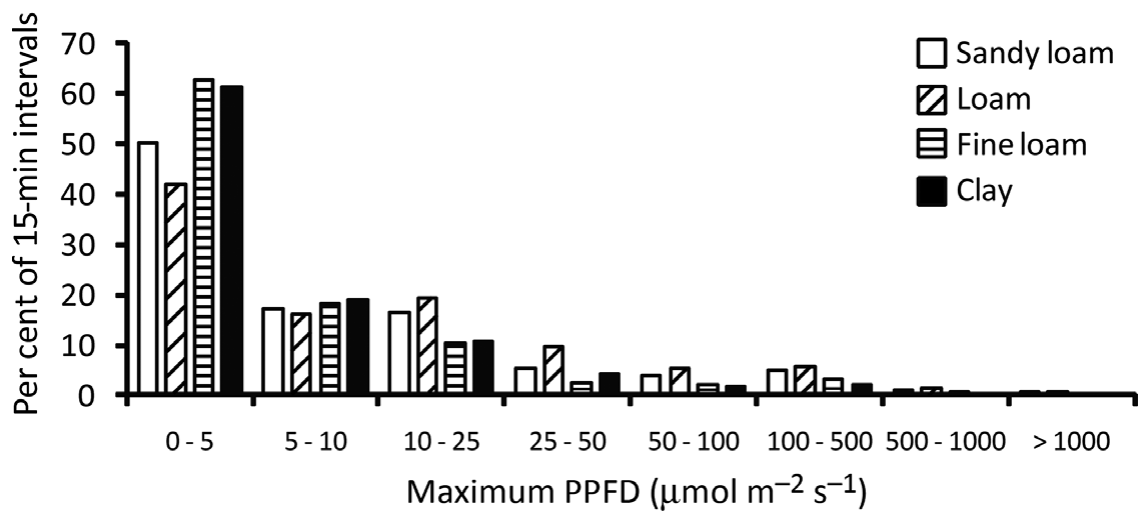

Figure 3. Distribution of the intensity of sunflecks in the understorey of Bornean rain forest underlain by four soil types. The per cent of daytime 15-min intervals in which the maximum photosynthetic photon flux density (PPFD) fell into each light intensity class is shown for the understories of sandy loam, clay, loam and fine loam soils, across all sampling dates, locations and sensors within soil type and season. The inset shows comparisons between forest types in the early monsoon season (November 2007) based on all sampled locations (189 sensor-days at 7 (loam and fine loam) and 14 (sandy loam and clay) locations per forest type), and the main chart shows comparisons based on the subset of those locations that were also sampled in the monsoon season (a). The main chart shows comparisons between forest types in the non-monsoon season (May 2008 ; 162 sensor-days at 6 (loam and fine loam) and 12 (sandy loam and clay) locations per forest type) (b).

of which is influenced by other resources, such as soil nutrients and water availability, and disturbance. We found evidence of such feedbacks involving above- and below-ground resources: there was significant variation in both total daily PPFD and sunfleck frequency and intensity in the understorey of forest growing on four soil types along an edaphic gradient in Borneo. Although the number of sample locations on each forest type was limited, the results we obtained using PAR sensors were consistent with a study of two of these forest types using 98 hemispherical photographs, which found saplings in the understorey on sandy loam to experience $6 \%$ greater canopy openness compared with those on clay soil (Russo et al. 2010). Rank differences in understorey light regimes between soil types were consistent between seasons, although above-canopy PAR was lower in the monsoon, relative to the non-monsoon, season. In addition to this soil-related variation, we also found understorey light regimes to vary strongly at finer spatial scales within a forest type and to vary with the slope of the land surface for two forest types.

\section{Causes and consequences of soil-related variation in light regimes}

In our study, forests on the different soil types varied in several edaphic factors, including soil texture, soil nutrient and water availability, elevation, slope, and aspect. The independent effects of all of these factors cannot be distinguished here, but we nevertheless found significant soil-related effects on understorey insolation among these forest types. Our results are consistent with studies from tropical and temperate forests that also found understorey light availability to decrease with increasing availability of soil resources (Coomes \& Grubb 2000).We did not, however, find a simple pattern of monotonic decline, as forests on the intermediate soil types had 


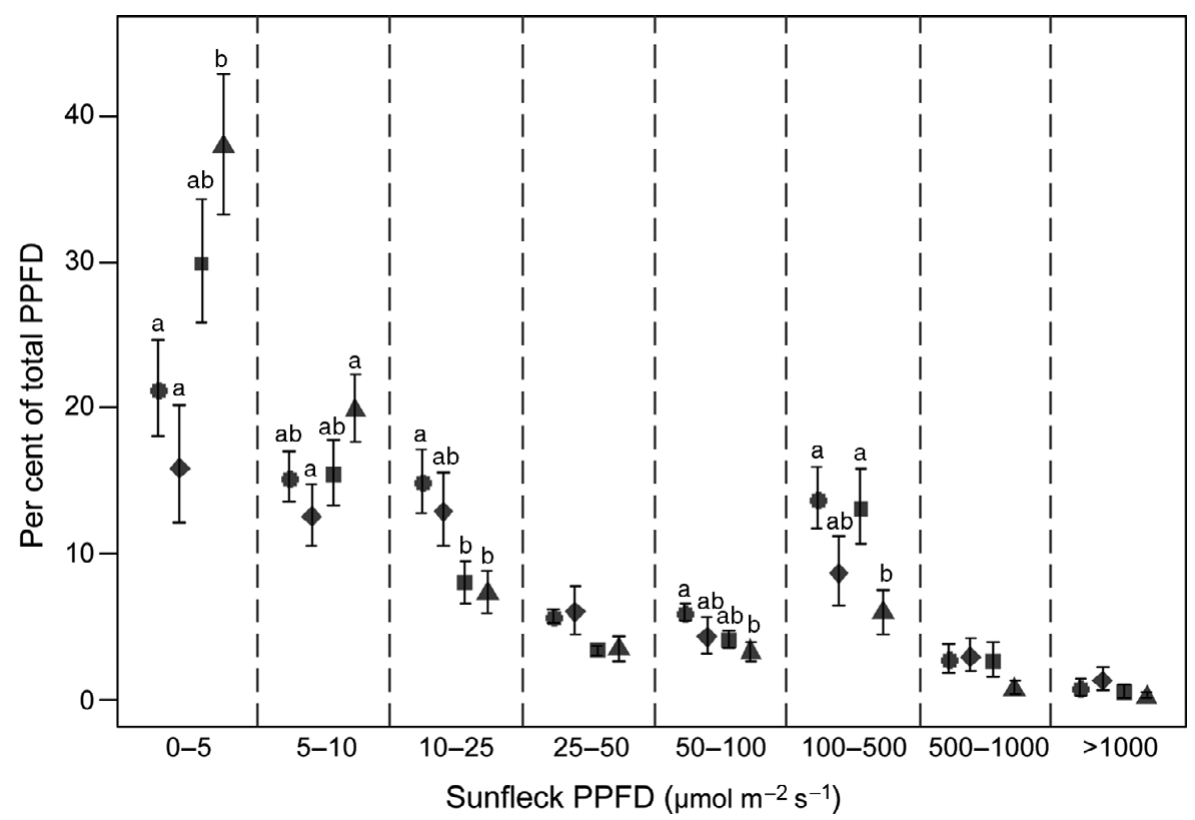

Figure 4. The per cent of total photosynthetic photon flux density (PPFD) over $3 \mathrm{~d}$ contributed by sunflecks of different PPFD in the understorey of Bornean rain forest underlain by four soil types in the non-monsoon season (May 2008). Points are means across sample locations, with standard error bars, grouped by sunfleck PPFD category. Different letters within each category indicate significant differences among soil types within that category, based on univariate tests after a significant overall multivariate analysis of variance. For categories lacking letters, there were no significant differences among soil types. Symbols: circle, sandy loam; diamond, loam; square, fine loam; triangle, clay.

(a) $0-5 \mu \mathrm{mol} \mathrm{m} \mathrm{m}^{-2} \mathrm{~s}^{-1}$

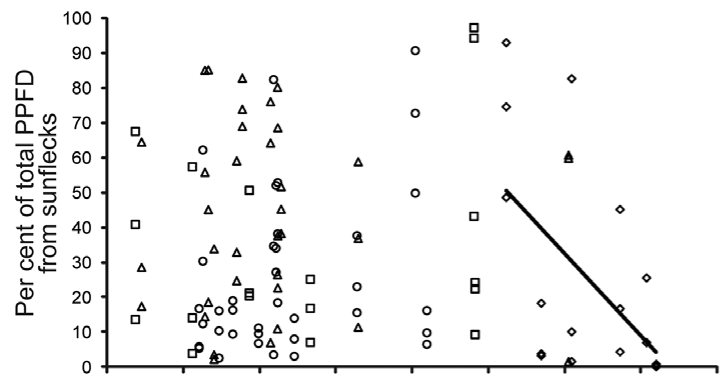

(c) $50-100 \mu \mathrm{mol} \mathrm{m} \mathrm{m}^{-2} \mathrm{~s}^{-1}$

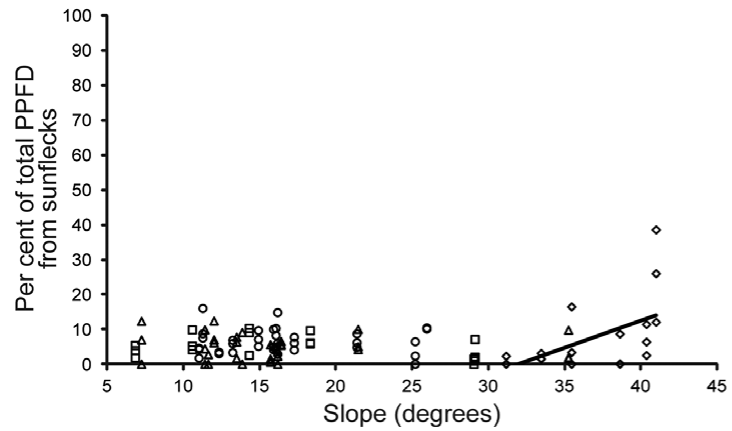

(b) $25-50 \mu \mathrm{mol} \mathrm{m}^{-2} \mathrm{~s}^{-1}$

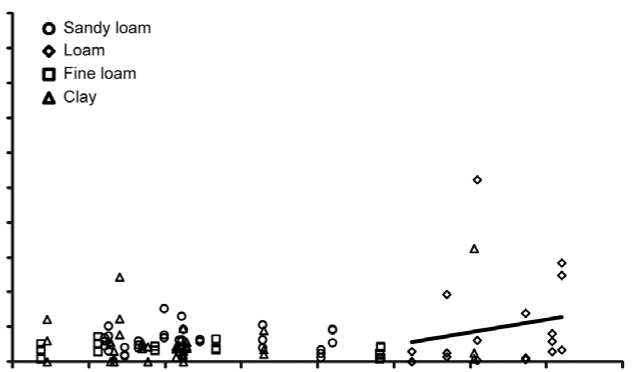

(d) $100-500 \mu \mathrm{mol} \mathrm{m}^{-2} \mathrm{~s}^{-1}$

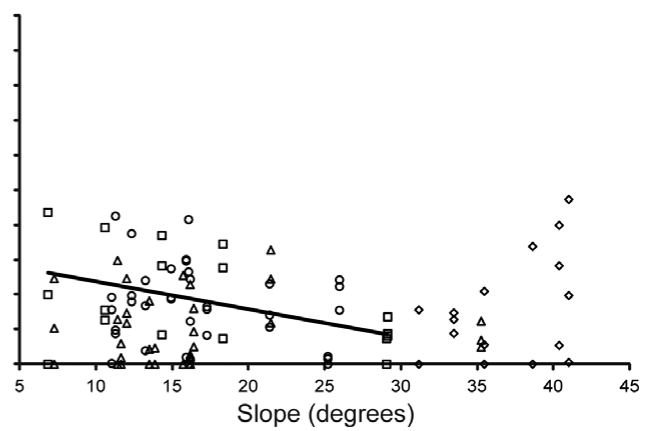

Figure 5. Variation between slope and the per cent of total photosynthetic photon flux density (PPFD) over $3 \mathrm{~d}$ contributed by sunflecks of different PPFD in the understorey of Bornean rain forest underlain by four soil types in the non-monsoon season (May 2008). Only sunfleck PPFD categories with a significant interaction between forest type and slope are shown: $0-5 \mathrm{umol} \mathrm{m}^{-2} \mathrm{~s}^{-1}$ (a), 25-50 umol m $\mathrm{um}^{-2} \mathrm{~s}^{-1}$ (b), 50-100 umol m${ }^{-2} \mathrm{~s}^{-1}$ (c), and 100-500 umol m $\mathrm{m}^{-2} \mathrm{~s}^{-1}$ (d). Points represent sample locations, with the least-squares regression lines for forest types having a non-zero slope of the relationship between per cent of total PPFD and slope. 
greater light availability than those at either end of the gradient. This was always true for the forest on the loam soil, but only true for the fine loam soil in the early monsoon season, largely due to one location on fine loam near a large gap from a landslip that was sampled in the early monsoon, but not the non-monsoon, season.

The within and between forest-type variation in light regimes at Lambir may have several origins. First, the four forest types examined here occur within a 52-ha area, and so do not result from variation in rainfall. Nevertheless, due to differences in soil texture, elevation and slope, the same rainfall produces significant variation in water availability in each forest type (Russo et al. 2010). Despite constant rainfall, our results comparing irradiance in forests on sandy loam and clay are still consistent with studies along rainfall gradients, which generally have found leaf area index to decrease in parallel with water availability, accompanied by an increase in light penetration (Coomes \& Grubb 2000). Second, the variation in light transmission among the forests along this edaphic gradient is likely to be related to the divergent leaf and crown traits of the tree species comprising the different assemblages associated with each soil type. Average leaf size of canopy trees is larger on the clay and fine loam than on the sandy loam or loam soil types at Lambir (Ashton 1964, Ashton \& Hall 1992), which would reduce PAR transmission to the understorey. Variation among the different forest types at Lambir in the sizes of canopy leaves, which are better lit, is most likely a consequence of differences in soil resource supply, since leaves with larger specific leaf area are generally found on soils with greater nutrient and water availability (Wright et al. 2002; S. E. Russo, unpubl. data). Furthermore, the decreased penetration of light on clay occurs in opposition to the generally shorter leaf life spans of the clay specialists (S. E. Russo, unpubl. data), in parallel with forests on soil gradients in the temperate zone (Coomes \& Grubb 2000). Third, the four forest types vary not only in belowground resources, but also in slope. The loam soil and parts of the fine loam soil comprise steep slopes with greater occurrence and larger sizes of landslips than do the clay, low-lying parts of fine loam, and sandy loam soils (Ohkubo 2007a, 2007b; Yamakura et al. 1996). Steep slopes would result in larger, more frequent canopy openings and could explain why the decline in understorey irradiance was not monotonic with increases in soil resource availability. In addition, forest types differed in the relative impact of slope versus other edaphic factors, such as resource availability, on understorey insolation. Because they differed the least in slope, comparisons between forests on clay, fine loam and sandy loam are likely to better reflect the effect of soil texture differences than of slope on understorey irradiance. In contrast, the steep slopes of loam likely explain why the understorey on this forest type had the highest insolation, since only in this forest type did slope correlate strongly with total daily PPFD and sunfleck frequencies and intensities.

Although we found significant soil-related differences in understorey irradiance among forest types, there was also substantial spatial variation within forest types. Tree species composition shifts dramatically among forests on these soil types (Davies et al. 2005), but the spatial distribution of species, even for soil specialists within forest types, also varies considerably. Spatial turnover in species composition within forest types likely contributes to finer-scale spatial variation in light transmission due to interspecific differences in leaf and crown traits (Canham et al. 1994, Turner et al. 2000). Furthermore, although most tree species distributions are strongly associated with categorically defined soil habitats (Davies et al. 2005), the within-soil variability in understorey irradiance suggests that finerscale continuous variation in soil resources may also influence the species composition and leaf and crown traits that ultimately determine light transmission.

The different light regimes among the forest types along this edaphic gradient may have several consequences for forest structure and dynamics. It is well-established that even small differences in photosynthetic photon flux density (PPFD) and the frequency and intensity of sunflecks affect the growth of seedlings and saplings in the understorey (Chazdon 1986, Koizumi \& Oshima 1993, Leakey et al. 2003, 2005; Zipperlen \& Press 1997). We found that statistically similar total daily PPFD among these Bornean forest types nonetheless resulted from different distributions of sunfleck frequency and intensity, as did Chazdon (1986). Assuming that trees have the physiological capacity to respond to dynamic irradiance, we would expect these differences to translate into different photosynthetic responses, consequences for carbon gain, and growth rates (Chazdon \& Pearcy 1991, Leakey et al. 2005). At Lambir, maximum rates of carbon assimilation are faster on average for tree species that specialize on the sandy loam soil type, compared with clay, which is contrary to expectations based only on soil resource availability (Russo et al. 2010). However, the reduced soil resources on sandy loam soil may ultimately limit carbon gain or shift carbon allocation below-ground or to making longer-lived tissues, since juvenile trees on this soil have the slowest diameter growth rates (Russo et al. 2005). The fastest diameter growth rates are achieved by trees on the loam and fine loam soils, followed by those on clay (Russo et al. 2005), paralleling the differences in PPFD and dynamic irradiance for these three soil types. These patterns suggest that competitive dynamics among juvenile trees may be dominated more by soil resource availability at the resource-poor end of this edaphic gradient and by understorey irradiance at the other end, as would be predicted by Tilman (1988). Faster predicted tree height growth, based on empirically 
parameterized allometric growth models, of tree species specializing on the clay soil, relative to sandy loam specialists, is consistent with this hypothesis (Heineman et al. 2011).

Differences among forest types in the frequency of sunflecks of varying intensities may also lead to soilrelated differences in the range of light-regeneration niches available, resulting in diversification of tree crown and height allometries and allometric growth rates (Coomes et al. 2009, Heineman et al. 2011, Poorter \& Arets 2003). Ultimately, these shifts in photosynthetic carbon gain and allometric growth responses are expected to sort tree species among soil habitats, resulting in differences in composition among forest types. Consistent with this idea, the frequency of light-demanding, fastgrowing tree species is greater on the loam and fine loam soil types (Russo et al. 2005), which would further reinforce soil-related patterns of variation in light regimes due to increased light transmission through the canopies of early-successional species (Canham et al. 1994, Coomes \& Grubb 2000).

\section{Conclusions}

Beyond the importance of understanding the causes and consequences of the plant-soil feedbacks generating soil-related variation in understorey light regimes, our study has implications for the methods used to infer factors important in the assembly of and competitive interactions in forest communities. First, our results bring renewed attention to the need to consider multiple resource dimensions when testing hypotheses about environmental factors driving plant community structure and dynamics along gradients (Chapin et al. 1987, Pearson et al. 2003). The availability of different resources along gradients can vary in opposing directions, generating opposing environmental selection pressures and hampering inferences concerning the relative importance of different abiotic factors in the assembly and functional trait variation of plant communities.

Second, basal area is often used as a metric of neighbourhood competition in forests, with greater basal area implying a shadier environment (Canham et al. 2006). At Lambir the forest on sandy loam has greater basal area and stem density compared with the forest on clay (Davies et al. 2005, Lee et al. 2002), yet understorey light availability varies in the opposite direction. These findings suggest that the relationship between standing basal area and light transmission to the understorey is not the same between these two forest types. It is therefore important to account for variation due to soil types when using standing basal area as a measure of competition for light between forest types in which floristic composition (Davies et al. 2005), leaf functional traits (S. E. Russo, unpubl. data) and canopy leaf structure (Ashton 1964, Ashton \& Hall 1992) differ as greatly as they do between the forests on the different soil types at Lambir.

\section{ACKNOWLEDGEMENTS}

The authors thank the Sarawak Forest Department and Forest Research Corporation for their kind permission to conduct research in Lambir Hills National Park. The 52-ha Long-Term Ecological Research Project is a collaborative project of the Forest Department of Sarawak, Malaysia, Harvard University, USA (under NSF awards DEB-9107247 and DEB-9629601 to P. S. Ashton), and Osaka City University, Japan (under Monbusho grant 06041094 to T. Yamakura, 08NP0901 to S. Tamura and 09NP0901 to S. Sasaki). Financial support was also provided by the University of Nebraska - Lincoln through a Faculty Seed Grant and a Jane Robertson Layman Award. Thanks also to David Billesbach and Tanvir Shah for assistance with sensors and programming data loggers and to Steve Portnoy for advice concerning statistical analysis.

\section{LITERATURE CITED}

AGRESTI, A. 1990. Categorical data analysis. John Wiley and Sons, New York. 558 pp.

ASHTON, P. S. 1964. Ecological studies in the mixed dipterocarp forests of Brunei state. Oxford Forestry Memoir 25:1-75.

ASHTON, P. S. \& HALL, P. 1992. Comparisons of structure among mixed dipterocarp forests of north-western Borneo. Journal of Ecology 80:459-481.

BAILLIE, I. C., ASHTON, P. S., COURT, M. N., ANDERSON, J. A. R., FITZPATRICK, E. A. \& TINSLEY, J. 1987. Site characteristics and the distribution of tree species in mixed dipterocarp forest on Tertiary sediments in Central Sarawak, Malaysia. Journal of Tropical Ecology 3:201-220.

BAILLIE, I. C., ASHTON, P. S., CHIN, S. P., DAVIES, S. J., PALMIOTTO, P. A., RUSSO, S. E. \& TAN, S. 2006. Spatial associations of humus, nutrients, and soils in mixed dipterocarp forest at Lambir, Sarawak, Malaysian Borneo. Journal of Tropical Ecology 22:543-553.

BARKER, M. G., PRESS, M. C. \& BROWN, N. D. 1997. Photosynthetic characteristics of dipterocarp seedlings in three tropical rain forest light environments: a basis for niche partitioning? Oecologia 112:453-463.

BRUNIG, E. F. 1974. Ecological Studies in the Kerangas Forests of Sarawak and Brunei. Borneo Literature Bureau, Kuching. 237 pp.

BURNHAM, K. P. \& ANDERSON, D. R. 2002. Model selection and multimodel inference: a practical information-theoretic approach. Springer, New York. 353 pp.

CANHAM, C. D., FINZI, A. C., PACALA, S. W. \& BURBANK, D. H. 1994. Causes and consequences of resource heterogeneity in forestsinterspecific variation in light transmission by canopy trees. Canadian Journal of Forest Research 24:337-349. 
CANHAM, C. D., PAPAIK, M. J., URIARTE, M., MCWILLIAMS, W. H., JENKINS, J. C. \& TWERY, M. J. 2006. Neighborhood analyses of canopy tree competition along environmental gradients in New England forests. Ecological Applications 16:540-554.

CHAPIN, F. S., BLOOM, A. J., FIELD, C. B. \& WARING, R. H. 1987. Plant responses to multiple environmental factors. Bioscience 37:49-57.

CHAZDON, R. L. 1986. Light variation and carbon gain in rain forest understorey palms. Journal of Ecology 74:995-1012.

CHAZDON, R. L. \& FETCHER, N. 1984. Photosynthetic light environments in a lowland tropical rain forest in Costa Rica. Journal of Ecology 72:553-564.

CHAZDON, R. L. \& PEARCY, R. W. 1991. The importance of sunflecks for forest understory plants-photosynthetic machinery appears adapted to brief, unpredictable periods of radiation. Bioscience 41:760766.

CONDIT, R. 1998. Tropical forest census plots: methods and results from Barro Colorado Island, Panama and a comparison with other plots. Springer, Berlin. 207 pp.

COOMES, D. A. \& GRUBB, P. J. 1996. Amazonian caatinga and related communities at La Esmeralda, Venezuela: forest structure, physiognomy and floristics, and control by soil factors. Vegetatio 122:167-191.

COOMES, D. A. \& GRUBB, P. J. 2000. Impacts of root competition in forests and woodlands: a theoretical framework and review of experiments. Ecological Monographs 70:171-207.

COOMES, D. A., ALLEN, R. B., BENTLEY, W. A., BURROWS, L. E., CANHAM, C. D., FAGAN, L., FORSYTH, D. M., GAXIOLA-ALCANTAR, A., PARFITT, R. L., RUSCOE, W. A., WARDLE, D. A., WILSON, D. J. \& WRIGHT, E. F. 2005. The hare, the tortoise and the crocodile: the ecology of angiosperm dominance, conifer persistence and fern filtering. Journal of Ecology 93:918-935.

COOMES, D. A., KUNSTLER, G., CANHAM, C. D. \& WRIGHT, E. 2009. A greater range of shade-tolerance niches in nutrient-rich forests: an explanation for positive richness-productivity relationships? Journal of Ecology 97:705-717.

DALLING, J. W., HUBBELL, S. P. \& SILVERA, K. 1998. Seed dispersal, seedling establishment and gap partitioning among tropical pioneer trees. Journal of Ecology 86:674-689.

DAVIES, S. J., TAN, S., LAFRANKIE, J. V. \& POTTS, M. D. 2005. Soilrelated floristic variation in the hyperdiverse dipterocarp forest in Lambir Hills, Sarawak. Pp. 22-34 in Roubik, D. W., Sakai, S. \& Hamid, A. (eds.). Pollination ecology and rain forest diversity, Sarawak studies. Springer-Verlag, New York.

DENSLOW, J. S., ELLISON, A. M. \& SANFORD, R. E. 1998. Treefall gap size effects on above- and below-ground processes in a tropical wet forest. Journal of Ecology 86:597-609.

HARTSHORN, G. S. 1980. Neotropical forest dynamics. Biotropica 12:23-30.

HEINEMAN, K. D., JENSEN, E., SHAPLAND, A., BOGENRIEF, B., TAN, S., REBARBER, R. \& RUSSO, S. E. 2011. The effects of belowground resources on aboveground allometric growth in Bornean tree species. Forest Ecology and Management 261:1820-1832.

KOBE, R. K. 1999. Light gradient partitioning among tropical tree species through differential seedling mortality and growth. Ecology 80:187-207.
KOIZUMI, H. \& OSHIMA, Y. 1993. Light environment and carbon gain of understorey herbs associated with sunflecks in a warm temperate deciduous forest in Japan. Ecological Research 8:135-142.

LEAKEY, A. D. B., PRESS, M. C. \& SCHOLES, J. D. 2003. Patterns of dynamic irradiance affect the photosynthetic capacity and growth of dipterocarp tree seedlings. Oecologia 135:184-193.

LEAKEY, A.D. B., SCHOLES, J.D. \& PRESS, M. C. 2005. Physiological and ecological significance of sunflecks for dipterocarp seedlings. Journal of Experimental Botany 56:469-482.

LEE, H. S., DAVIES, S. J., LAFRANKIE, J. V., TAN, S., YAMAKURA, T., ITOH, A., OHKUBO, T. \& ASHTON, P.S. 2002. Floristic and structural diversity of mixed dipterocarp forests in Lambir Hills National Park, Sarawak, Malaysia. Journal of Tropical Forest Science 14:379400.

MATSON, P. A. \& BOONE, R. D. 1984. Natural disturbance and nitrogen mineralization: wave-form dieback of mountain hemlock in the Oregon Cascades. Ecology 65:1511-1516.

MCCULLACH, P. \& NELDER, J. A. 1989. Generalized linear models. Chapman and Hall, London. 511 pp.

MCGILL, B. J., ENQUIST, B. J., WEIHER, E. \& WESTOBY, M. 2006. Rebuilding community ecology from functional traits. Trends in Ecology and Evolution 21:178-185.

MONTGOMERY, R. A.\& CHAZDON, R. L. 2001. Forest structure, canopy architecture, and light transmittance in tropical wet forests. Ecology 82:2707-2718.

MONTGOMERY, R. A. \& CHAZDON, R. L. 2002. Light gradient partitioning by tropical tree seedlings in the absence of canopy gaps. Oecologia 131:165-174.

MYSTER, R. W. \& FERNANDEZ, D. S. 1995. Spatial gradients and patch structure on two Puerto Rican landslides. Biotropica 27:149-159.

OHKUBO, T. 2007a. Spatial and topographic patterns of canopy gap formation in a mixed dipterocarp forest in Sarawak, Malaysia. Tropics 16:152-153.

OHKUBO, T. 2007b. Spatial pattern of landslides due to heavy rains in a mixed dipterocarp forest, North-Western Borneo. Tropics 16:59-70.

PALMIOTTO, Р. A. 1998. The role of specialization in nutrient-use efficiency as a mechanism driving species diversity in a tropical rain forest. Ph.D. thesis, School of Forestry and Environmental Studies. Yale University, New Haven. 282 pp.

PAOLI, G. D., CURRAN, L. M. \& ZAK, D. R. 2006. Soil nutrients and beta diversity in the Bornean Dipterocarpaceae: evidence for niche partitioning by tropical rain forest trees. Journal of Ecology 94:157170.

PEARSON, T. R. H., BURSLEM, D. F. R. P., GOERIZ, R. E. \& DALLING, J. W. 2003. Regeneration niche partitioning in neotropical pioneers: effects of gap size, seasonal drought and herbivory on growth and survival. Oecologia 137:456-465.

PICKETT, S. T. A. \& WHITE, P. S. (eds). 1987. The ecology of natural disturbance and patch dynamics. Academic Press, London. 472 pp.

POORTER, L. \& ARETS, E. 2003. Light environment and tree strategies in a Bolivian tropical moist forest: an evaluation of the light partitioning hypothesis. Plant Ecology 166:295-306.

POTTS, M. D., ASHTON, P. S., KAUFMAN, L. S. \& PLOTKIN, J. B. 2002. Habitat patterns in tropical rain forests: a comparison of 105 plots in northwest Borneo. Ecology 83:2782-2797. 
RICHARDS, P. W. 1996. The tropical rain forest: an ecological study. (Second edition). Cambridge University Press, Cambridge. 600 pp.

RICKLEFS, R. E. 1977. Environmental heterogeneity and plant species diversity: a hypothesis. American Naturalist 111:376-381.

RUSSO, S. E., DAVIES, S. J., KING, D. A. \& TAN, S. 2005. Soil-related performance variation and distributions of tree species in a Bornean rain forest. Journal of Ecology 93:879-889.

RUSSO, S. E., CANNON, W. L., ELOWSKY, C., TAN, S. \& DAVIES, S. J. 2010. Variation in leaf stomatal traits of 28 tree species in relation to gas exchange along an edaphic gradient in a Bornean rain forest. American Journal of Botany 97:1109-1120.

TAN, S., YAMAKURA, T., TANI, M., PALMIOTTO, P., MAMIT, J.D., PIN, C. S., DAVIES, S. J., ASHTON, P. S. \& BAILLIE, I. C. 2009. Review of soils on the 52-ha long term ecological research plot in mixed dipterocarp forest at Lambir, Sarawak, Malaysian Borneo. Tropics 18:61-86.

TILMAN, D. 1988. Plant strategies and the dynamics and structure of plant communities. Princeton University Press, Princeton. 360 pp.

TURNER, I. M., LUCAS, P. W., BECKER, P., WONG, S. C., YONG, J. W. H., CHOONG, M. F. \& TYREE, M. T. 2000. Tree leaf form in Brunei: a heath forest and a mixed dipterocarp forest compared. Biotropica 32:53-61.

WATSON, H. 1985. Lambir Hills National Park: resource inventory with management recommendations. National Parks and Wildlife Office, Forest Department, Kuching, Sarawak, Malaysia.
WELLS, A., STEWART, G. H. \& DUNCAN, R. P. 1998. Evidence of widespread, synchronous, disturbance-initiated forest establishment in Westland, New Zealand. Journal of the Royal Society of New Zealand 28:333-345.

WHITMORE, T. C. 1978. Gaps in the forest canopy. Pp. 639-655 in Tomlinson, P. B. \& Zimmerman, M. M. (eds.). Tropical trees as living systems. Cambridge University Press, Cambridge.

WHITMORE, T. C. \& WONG, Y. K. 1959. Patterns of sunfleck and shade in tropical rain forest. Malayan Forester 22:50-62.

WRIGHT, I.J., WESTOBY, M. \& REICH, P.B. 2002. Convergence towards higher leaf mass per area in dry and nutrient-poor habitats has different consequences for leaf life span. Journal of Ecology 90:534543.

YAMAKURA, T., KANZAKI, M., ITOH, A., OHKUBO, T., OGINO, K., CHAI, O. K. E., LEE, H. S. \& ASHTON, P. S. 1996. Forest structure of a tropical rain forest at Lambir, Sarawak, with special reference to the dependency of its physiognomic dimensions of topography. Tropics 6:1-18.

YODA, K. 1974. Three-dimensional distribution of light intensity in a tropical rain forest of West Malaysia. Japanese Journal of Ecology 24:247-254.

ZIPPERLEN, S. W. \& PRESS, M. C. 1997. Photosynthetic induction and stomatal oscillations in relation to the light environment of two dipterocarp rain forest tree species. Journal of Ecology 85:491503. 